\title{
Into the Engine Room: An Inter-University Literature-Teaching Project Focussing on Narrative
}

\author{
David Owen, Carme Font, Laura Gimeno, Cristina Pividori \\ Department of English and German Studies, Universitat Autònoma de Barcelona, Spain
}

Article received 1 November 2012, Final version received 3 December 2012

This article sets out the objectives, approaches and organisational development of a still on-going inter-university literature-teaching project entitled 'Between the Lines: Comprehensive Reading of Literary Texts in a Foreign Language', which was awarded a two-year grant by the Catalan Agency for the Management of University and Research Grants, AGAUR (MQD 00121). As a means of countering students' excessive concern with essentially superficial aspects of literary texts and in order to facilitate their understanding of more complex textual issues, this project has systematically emphasised the issue of narrativity in literature teaching, thereby also helping students to approach their subject in a more technically sophisticated way in keeping with the demands of their degree. The article discusses the various phases of the project's implementation, with reference to the underlying problem that gave impetus to the initiative, as well as setting out its provisional conclusions.

\section{Introduction}

This article describes the objectives, approaches and workings of an inter-university teaching project in the ambit of literature. It has involved teachers from departments of philology at three Catalan public universities, as group members, and students at these universities taking degrees in foreign languages (English, French, Italian). The students were all at relatively early phases of their degree study, typically in their first or second year. The project — of two years' duration - is currently drawing to a close and will finalise at the end of December, 2012. Though we are not yet in a position to offer a definitive, global assessment of the project's results and outcomes, this current discussion provides a broad overview of how the project has been carried out and, in light of our experience, points to certain conclusions.

Our initiative grew from our collective belief that undergraduate students studying the literature of a foreign language frequently focus excessively on issues of plot and have difficulties in engaging with works at deeper and more technical levels of literary analysis. However, the broad purposes of literary criticism that are central to all degree study in literature-and which underpin class content, are the basis of critical studies used as 
bibliography and are the object of course evaluation - depend directly on the development by students of advanced reading and analytical skills required to successfully negotiate concerns such as understanding and recognising sources, stylistic considerations, characterisation, thematic concerns, gender and genre issues, historical context, etc. In this sense, then, we perceived that there was a considerable gap between students' initial understanding of what is involved in the study of literature at university level and what their degree courses were requiring of them.

As a means of bridging this gap between a superficial engagement with literary texts and the need for a far more profound understanding of how literature works (the need, so to speak, to get into the engine room and see how 'the machine' actually functions), we decided to centre our teaching of the various texts within our degree programmes on the question of narrative, since this issue very effectively brings together a range of technical questions in a manner that can relatively easily be perceived, analysed and discussed. Essentially, a fuller comprehension of how a text's 'narrativity' is constructed (typically, though not exclusively, through the literary figure of a narrator) facilitates study of the means by which an author develops and arranges aspects of the work in question for highly specific purposes and for clearly determinable effects. A simple illustration of this is the means by which a narrator will modulate aspects of a specific character's presentation, providing positive or negative information, in order thereby to manipulate readers' reactions so that their sympathy or antipathy to such a character has been subliminally engaged. Once this has been established, related thematic concerns may then be brought into play. Our concern has principally been with narrative in the Novel, where it is more readily identifiable; nevertheless, our approach - which we set out in much fuller detail below-is applicable to any genre of writing, since some form of narrative agency is always present. The project itself, then, is the consolidation of these teaching ideas into a relatively formal structure of a teaching-practice group within which which all participating members approached their classes with the same basic purpose and through the same underlying approach. Although our group has no formal name, we refer to it as the Literature MQD Group, the Catalan initialism "MQD" signifying "millora de qualitat docent", which translates as "improvement in teaching quality".

This article sets out our undertaking, the perceived difficulty that gave rise to the project, its fundamental objectives and the activities that have been carried out to date. It also briefly describes the organisation and working procedures of the MQD group. As has already been mentioned, the project — though now in its final phase - is still on-going. In that sense, 
in this article we provide only partial conclusions, though it should also be said that our impressions and the informal feedback that we have received point very clearly in the same (positive) direction.

Our discussion is organised as follows: Part One provides a fuller introduction to the project, its members and the students who participated, its motivation and its fundamental objectives. Part Two discusses our methodology, the working plan according to which the project has been carried out, and the results that have to-date been obtained. We then set out our conclusions.

\section{Part One: Reading the Lines}

\section{The Problem}

The project began with a small group of lecturers in English Literature at the Universitat Autònoma de Barcelona (henceforth UAB). We had perceived, as a perennial problem, that literature students at an early stage of their degrees had particularly inadequate expectations and understandings of what a close study of literature involved. Frequently, they had little inclination or indeed ability to go systematically beyond an entirely superficial discussion of the texts that they were studying, this discussion inevitably focussing on the most prominent element, which is plot.

Specifically, students taking a modern foreign-language degree face a series of challenges when confronted with the study of literary works. Besides the difficulty of studying in a foreign language, there are other elements such as the imperative need to discern the basic elements required for a proper analysis and understanding of literature. Many undergraduates in their early university years are not ready to discuss texts beyond the level and of plot and this has clear consequences on their reading and studying of literature at later stages in their degree. On the other hand, as we have already observed, the aim of the study of literature is to address issues that are far deeper than merely plot-oriented readings; this mismatch between the course objectives and our students' understanding of what the study of literary texts involves can create considerable confusion and may even lead to a sense of disorientation and disappointment on the part of the students. Clearly, the notion that students can learn to study literature effectively simply by reading is one that can be directly challenged: reading alone may do little more than establish storyline events. A far more directed approach by the instructor - we believed — was called for in order to help students grasp the fuller complexity of their subject, and in order to provide the framework by which 
students could develop the reflective and analytical skills required in the advanced study of literary texts.

These observations on this underlying problem were initially derived from views shared by a group of colleagues teaching English Literature at the UAB, and were also based on our students' views gained in literature tutorials. On the basis of these perceptions, we then pursued the issue along more theoretical lines and assessed the views of other teachers and researchers within this ambit. Amongst those works considered in this early phase, we particularly reviewed discussion by Durant, Mills and Montgomery (1988); Hickey and Reiss (2000); Watson (2005); Wisker and Robinson (2009); and (this at a later stage) Hancox and Muller (2011). In our assessment, it appears that there is a fortuitous agreement between these works and our own basic perceptions.

Durant, Mills and Montgomery take issue with the limitations of conventional literature classes that simply reinforce notions of canonicity, critical theory or stylistics but do not attempt to develop a deeper critical awareness or ability. They suggest instead a "hands-on" approach based on "experimental activity" (p.13), that is to say, on "problem-solving exercises" (p.17) in which students are encouraged to interrogate the texts and become actively involved in attempts to interpret them. Similarly, Hickey and Reiss suggest "a change in the structure of classroom authority" (p. xii) and assert the need for more relevant approaches to teaching that are, in turn, more fully engaging of students' critical abilities, incorporating new literature practices using technology, working with alternatives to formal assessment and theorising the practice and learning of multiple literacies (p. xvii). In a comparable approach, Watson (2005) mistrusts those teaching methods "based on the transmission of inert knowledge" (p.95) and highlights "the value of students' initial responses, which can then be refined in group or class discussion" (p.96).

Based on the Meyer and Land notion of "threshold concept" as a "particular basis for differentiating between core learning outcomes that represent 'seeing things in a new way' and those that do not" (p.1), Wisker and Robinson examine (at the level of postgraduate studies) how the focus on conceptual thresholds - their identification and surpassingimpacts positively on developing the effective critical study of literature. They encourage postgraduates to "explore their experiences, perceptions, reflections and the evidence upon which they make decisions about the achievement of disciplinary threshold concepts and the crossing of conceptual thresholds at postgraduate level” (p.320). 
Hancox and Muller, on the other hand, examine the prospective use of fictocriticism for undergraduate students through its implementation in a literature unit offering a fictocritical piece of assessment. They suggest that fictocriticism successfully bridges students' usual fixation on the superficial aspects of literary texts and the need to develop a more complex, deeper understanding of the multiple ambits of textual criticism.

Our aim to reassess the role of the literature of a foreign language at an undergraduate level by centring our teaching on the question of narrative also has theoretical grounding in the works of Showalter (2003), Mills (2008) and Severn (2008). Showalter connects aspects of the narrative to the teaching process by showing different ways in which the narrative frame of the classroom can be ruptured or broken. In her view, the negotiation of academic narrative could bridge the gap between the class and fiction, and illustrate the ways novels work, and the unconscious assumptions we make about readers (95-96).

For example, to cite studies based on specific classroom content, in teaching Shakespeare's Othello, Mills encourages students to "create some scenes that form some of the backstory (p.154) [...], recreating Shakespearean language and filling the gaps cleverly left in the dramatic action (p.158). Similarly, Severn uses The Good Soldier as a model text to approach the teaching of modernist novels in introductory-level literature courses through "innovative teaching techniques such as creative writing assignments" (p.141). Following related lines, Brown (2010) approaches the teaching of literary texts through a creative focus on reader subjectivity, highlighting "concerns about authorial credibility and likeability, as well as the ethics of writers and readers. In response, students (explore) the question of authorial authenticity in their work" (p.128).

At a more general level, in a study that is partly related to our own concerns, Davies (2006) worked with non-native speakers of English who take classes in literature. This was not specifically narrative focussed, centring instead on issues such as cinema adaptations and the relationship between conventional print and the internet. However, Davies reaffirms many of our own perceptions regarding students' superficial assumptions about the study of literature, namely, that it is "...simply composed of black and white certainties" (introduction), and the need to provide students with the means to access their subject in more technically assured ways, since "many students are not used to reading on a regular basis, and are, therefore, unlikely to have highly developed critical skills" (ibid).

Whilst none of these works directly engage with the problematics that we had encountered, they nevertheless approximate significantly to our concerns by underlining the 
need for far greater awareness of the multiple requirements and competences that the study of literature calls for, and in this sense reinforced our perception that students needed help in developing a more structured understanding of how texts work and what component features are key to an understanding of their functioning.

\section{Organisation}

On this basis, we then began discussions with colleagues from other philologies (specifically, French and Italian) and subsequently with colleagues in English Literature from other local universities (the University of Barcelona/UB and the Pompeu Fabra University of Barcelona/UPF). On confirming that our ideas were broadly shared and that the problems we had concerned ourselves with were generally seen as a common obstacle to effective literary study, we then took the decision to formalise our perceptions into a teaching project.

Under the group leadership of Professor Andrew Monnickendam of the UAB, we set up an inter-departmental, inter-university literature-teaching group and, defining the problem outlined above, applied in 2010 for a two-year Catalan government teaching-improvement grant (known as an 'MQD' project: millora de la qualitat docent). The official title of the MQD project is "Between the Lines: Comprehensive Reading of Literary Texts in a Foreign Language". The project was successfully evaluated and awarded the grant by the Catalan Agency for the Management of University and Research Grants, AGAUR (MQD 00121).

The group consists of 14 members, 11 from the UAB (eight from English Studies, three from Romance Studies), two from the UB and one from the UPF. Jointly, over the twoyear period of the project, we would be working with 23 university literature classes. These classes, as we have already indicated, were first- and second-year literature groups pertaining to the Bologna-style four-year degree in foreign languages, known in Catalonia as the Grau. Students were typically aged between 18 and 20, and theoretically had — on average - an upper-intermediate to advanced level of language competence. In reality, students in all classes show a considerable range of language abilities, and it is not unusual to find nearnative users of the language with classmates whose abilities are, at best, intermediate. This picture is complicated further by the frequent attendance in such classes of Erasmus exchange students (most usually from Italy, France, Germany, The Netherlands and The United Kingdom), whose language abilities range from broadly comparable to that of the Catalan students through to first-language users. 


\section{Basic Objectives and General Considerations}

Our aim was to reinforce our students' skills so as to facilitate their development into what we term "professional readers"; this involved assisting them to read beyond the surface-level interest of plot alone, and providing means for discerning the creative construct of a particular literary text and how this is established in a complex series of ways, a clear understanding of which is crucial to an effective study of literature. Our initial objective in addressing this challenge was to highlight the importance of the narrative persona in literary works of diverse generic form, historic origin and language, thus encompassing all genres of literature, and not exclusively the more usual focus of narrative studies, which is the novel or short story.

We also focused on literary fiction from earlier periods of literature as well as that produced in recent decades. Our frame of reference was to embrace literary representations of a proven and consolidated value (works of an unquestionable canonical status) in addition to relevant contemporary writing of broad reputation in order to emphasise the fundamental creative value of the narrator and its perennial significance.

By exploring the nature and function of the narrator (epistolary, third-person, omniscient, etc.) or that of the implicit narrative view (of relevance when studying genres such as Drama and Poetry, in which this literary device may not be explicitly present), our aim was to intervene directly in our students' understanding of the value of active, critical reading and, as a result, to improve their awareness of the means by which the authors of the works being studied developed their specific artistic 'agendas'. Such agendas, as perceived through the narrator (or narrative surrogate), comprehend the construction of moral or ethical frameworks within which to contextualise the themes and action of the work itself, the attribution of sympathy or antipathy towards particular characters, and the ways in which the readers is directed towards specific interpretations, favouring certain readings over others.

The project aimed, in this way, to address the following issues: (1) the separate entities of narrative persona and author (an evident distinction, fundamental to all critical appreciation yet simultaneously one that is frequently confused or misunderstood at initial levels of literary study); (2) the consequences, on the analysis of literary texts, of understanding that there all narrators are-in a pragmatic, stylistic sense-to some extent untrustworthy; (3) the need to confer the status of literary 'character' to the narrator, even when this figure is not strictly visible in the text; (4) the need to engage with contemporary readers' probable response to the narrator and his/her apparent aims (that is, the need to 
attempt historically valid readings); (5) generally, an emphasis on comprehending that all narrative involves a complex relationship with the reader that is never passive or "innocent", that requires close and careful analysis and that demands of the critical reader an active and enquiring approach to the text.

Through developing our students' understanding of this crucial aspect of literature, we aimed not only at facilitating the ability to read, evaluate and discuss literary texts in a more fully engaged and critical manner in order to transcend a common inclination or disposition amongst undergraduate students to limit literary assessment to the purely plotbased (as we have already made clear) but also to provide students with, in effect, a 'professional' vision of how literature actually works. Our hope is that other still-more advanced forms of assessing literary works would then become more transparent and accessible by having successfully connected with this aspect of critical reading and having realised the need of what we term 'the professional reader' to become a visceral, intimate part of the narrator's network of literary objectives when setting out the plot.

\section{Part Two: Reading between the Lines Group Coordination and Communication}

As an overview of the structure and functioning of the group, it suffices to say that it has a central coordination team, with other ambits of responsibility (conferences, publications, etc.) assigned to specific members.

The group established monthly meetings (though not necessarily involving all members in each session) in which to discuss and monitor classroom practice related to the project's aims, bringing to light specific issues concerning research or class-based issues.

\section{Framework}

The framework for approaching the discussion of texts and for emphasising their narrative strategies and concerns was grouped according to the following ambits:

1. Appraising the quality and purpose of the narrator within the narrative and assessing key issues affecting this, in accordance with our objectives and the impact of Reader-Response Criticism. ${ }^{1}$

2. Analysis of readers' involvement with narrative development by understanding the narrator's appeals to this involvement. 
3. Assessment of narrative surrogacy and the manner in which it acts in precisely parallel ways to the formal narrator in related but distinct genres (film, drama and poetry).

4. Evaluation and comprehension of extra-textual objectives that may be achieved through narrative orientation (for example, the literary expression of social, political or other cultural beliefs, orientations or ideologies that may be established or challenged through narrative strategy).

5. Appraisal of the correlation between narrative type and literary form (for example, the need to recognise that epistolary form, whether that of the traditional novel-in-letters or other types such as the diary or, in more contemporary writing, electronic correspondence, necessarily involves a first-person narrator whose connection with the reader and whose means of communicating plot is fundamentally distinct from the universal, third-person narrator).

It was not the intention of the MQD group to impose this framework onto the usual approach taken by the group members in their teaching, but rather to provide a general orientation of text analysis and class discussion in terms of the five main points. However, one of the main teaching advantages of this framework - apart from what we believe to be its obvious value to the student-is that it can fit in practically seamlessly with what most teachers would anyway be doing in their classrooms. It is not obtrusive to usual teaching practice and does not oblige teachers to prepare their material in ways that are significantly distinct from normal course considerations; it merely requires that a distinct angle of approach be emphasised over and above other means of discussing the texts. In effect, the framework functions as a methodological check-list that will necessarily be of greater or lesser relevance depending on the nature of the text under study, but which at all times assists the teacher in drawing critical attention to specific literary aspects at key points throughout the course.

The practical implementation of this framework has involved both conventional attendance-based classroom teaching and tutorials, which were carried out during the normal teaching activity and timetable of each member of the group. These tutorials, usually held on a monthly basis, focused on the students' further reflection on a narrative approach to literature and on any particular concerns or difficulty that may have arisen in class and that had not been sufficiently clarified at the time. However, several aspects involving the students' guided reaction towards reflecting more profoundly on narrative perspective were 
also added to the more conventional assessment (via examination, class papers or class presentations) of the texts being taught. This guided response included student questionnaires aimed at encouraging critical reflection on the teaching and learning processes, which are discussed more fully later in this article; in-class group presentations of narrative-related issues pertaining to the texts under study; close-reading exercises with comprehension-type questions focussing primarily on narrative concerns; and - at all stages - directed in-class discussion placing emphasis on narrative strategy.

Since most literature courses traditionally establish a class paper as a principal element of evaluation, all MQD members were encouraged to set essay assignments that focused on highly specific pragmatic, stylistic and narrative aspects of the literary works in question. This range of activities has been supported by the use of virtual teaching tools, principally through our institutions' teaching-intranet service and/or Moodle applications, or through class blogs, allowing for course content to be communicatively strengthened and for the provision of supplementary material, debate and dialogue. The use of such educational technology has unquestionably contributed to a fuller realisation of our project's objectives.

\section{The MQD Work Plan}

The project established three principal phases for its application and practice.

Phase 1: Planning. This phase logically involved initial preparation for applying the objectives of the project itself. Specifically, this meant identification of the most adequate texts within each participant's teaching programme that best suited our aims; the design of activities to be applied during the project and for its assessment; preparation and publication of a first MQD group conference presentation and/or article detailing the project, its general objectives and expectations ("Not Just What It Means, but also How It Means: Teaching Better Reading Skills to University Students of Literature").

Phase 2: Execution. This central phase ran —at least in theory-from January 2011 to July, 2012. In fact, administrative difficulties with the official confirmation of grant awards obliged us to postpone the start of this phase for a number of months, though ultimately this has not greatly affected the project's application, activities or objectives. The duration of this second phase therefore allowed MQD members to select suitable groups running at any point from the second semester of the 2010-2011 academic year, and the first and/or second semester(s) of the 2011-2012 academic year, bearing in mind that certain subjects are of one semester only, whereas others are annual. As we have observed, the classroom activities 
underpinning the project most probably already formed an integral part of the participants' normal teaching practice and therefore were in accordance with their lectures. However, the planning of the classes themselves needed to take into account the incorporation-at a time to be decided in each case by every individual group member-of the activities set out in 2.ii, namely student questionnaires; group presentations; close-reading exercises and in-class discussion. This phase was monitored by the monthly meetings held at the UAB led by the project leader or coordinating team, providing an opportunity to ensure that the agreed activities were being carried out, and for attending group members to discuss any partial results as well as to raise problems or concerns. This phase also contemplated the preparation of a conference presentation and/or article outlining the teaching-learning experience of the group members and of their students ("Reading and Meaning: Teaching Narration and Interpretation in a Multilingual Context”. INTED2012 Proceedings).

Phase 3: Data Collection and Assessment; Diffusion of Results; Further Activities. All data collected throughout the project, in addition to the observations made by group members in the monthly meetings has been organised and classified. In large part for this very purpose, we decided on the incorporation of an administrative-support colleague for the final phase of the project. As might be expected for a literature project, our data is essentially qualitative: we have therefore followed conventional guidelines for the assessment of such information within an educational context (see, for instance, "Quality in Qualitative Evaluation: a Framework for Assessing Research Evidence" inhttp://www.gsr.gov.uk/evaluating_policy/era_papers/qual_eval.asp.). This phase also establishes the need for the preparation of articles detailing the project in its three phases, its results and - where possible - its conclusions in both national and international journals. The project will also be presented, and its conclusions discussed, in a one-day teaching conference to be held in the UAB in December 2012, with a plenary session given by Professor Henry Widdowson. Further activities planned for the wider diffusion of the project, now in terms of its practical applicability to the university-teaching context, are two interrelated publications: (a) a teachers' manual for approaching the teaching of texts in the literature class; (b) a collection of essays discussing means of approaching texts in the literature class in light of the experience gained over the project's duration. 


\section{Results}

As we have observed, though this project is now at a very late stage, we are not currently in a position to offer definitive results. It should also be noted that the concept of a 'definitive' result is one that does not apply in a direct or meaningful sense to this undertaking in that sense that our essential enquiry (which we might summarise in the question "does a focus on the narrative in the literature class positively affect students' ability to analyse, criticise and discuss literary texts in a more technically complex manner than if the teaching had not given centrality to this aspect?") can give rise to a variety of equally valid responses. Additionally, it is clear that we need input both from teachers and students on this, particularly-once this question has been posed-in order to ascertain how the responses can be gauged and validated.

Regarding teacher response, we are (at the time of writing this) currently preparing the conclusions to this general narrative approach, which will be presented in the December 2012 conference. However, informal feedback from most of the group members would appear to support the validity of this focus, and to do so emphatically, in that it has forced students to see - at an early stage in their degrees - that the study of literature is not a vague, impressionistic affair that revolves around arbitrary opinions expressed on issues of plot, but instead involves a broad and interconnecting series of aspects that can be systematically approached, assessed and evaluated, and that this in turn - though initially perhaps rather complex and unexpected to students at this level-actually facilitates a fuller and more successful engagement with course content. In a similar vein, though less directly expressed, the consensus of students' opinion given in tutorials also appears to validate this focus as a more tangible means by which to approach a subject that many philology students see as nebulous and somewhat intractable, particularly in contrast to more 'measurable' subjects such as morphology, phonology or syntax.

Simultaneously to the understanding of the study of literature as going beyond content-based interpretations, both teachers and students have expressed the need to develop a new relationship to the acquisition of literary knowledge, more rooted in the idea of maximising the opportunities for active class interaction. This way, the literature class would involve the teacher's listening as much as lecturing, but most importantly, a shift from ensuring that students interpret texts in a single 'correct' manner towards helping them learn to explore their growing understandings of what they read. Literature is an appealing medium in which both teachers and students can effectively enlarge, scrutinise, and support 
interpretations. However, in order to do so, notions of what counts as literary knowledge will need to be revised.

In this latter question, however, we can at this stage forward at least partial results from our student questionnaires. This information is currently being assessed for much fuller treatment and analysis, but - as a means of objectively contrasting the views expressed in our informal feedback - even incomplete results may be a useful indicator.

We produced two questionnaires: one administered at the end of the first semester in which students had been focussing on narrative concerns; the second-shorter, and given at the end of the second semester for annual subjects - was administered to a far smaller number of groups for the purposes of contrast. In all, 29 questionnaires were administered ( 22 from survey 1; 7 from survey 2), for which we received responses from a total of 501 respondents (412 from survey 1; 89 from survey 2). The questionnaires were accessible online (via SurveyMonkey: http://surveymonkey.com) and had a specific response period associated with them, in every case of four calendar weeks from date of first notification by the course teacher. For subsequent analysis, questionnaires were coded according to university, department, teacher and subject, but all responses were-of course-anonymous. Questions were in English for English studies, but the MQD colleagues for Italian and French opted to administer their questionnaires in Catalan, for which translation was provided.

Questions from the first survey were as follows:

1. Beyond language comprehension, what is the first aspect of a work that you generally concern yourself with? Plot

Characterisation

Literary Stylistics

Sources and Influences

Other (please specify)

2. Have you previously confused the distinction between author and narrator?

Yes

No

Not sure

3. Do you now see this distinction more clearly?

Yes

No

Not sure

4. For you, the narrator is:

Just another character

Another character, but different from the rest

Not a character at all

Something else (please specify)

5. Is an omniscient narrator plausible to you?

Yes

Bellaterra Journal of Teaching \& Learning Language \& Literature. 5.4

(Nov-Dec 2012): 1-19. ISSN 2013-6196. 
No

Not sure

Please explain the reasons for your answer

6. Do you feel that you can 'trust' a third-person omniscient narrator more than a first-person narrator?

Yes

No

Not sure

Please explain the reasons for your answer

7. What do you understand by the expression 'an unreliable narrator'?

A narrator who never directly identifies him/herself to the reader

A narrator who insists on speaking directly to the reader

A narrator who is actually part of the story (i.e., involved in its events and action)

Something else (please specify)

8. Has a focus on the narrator/narrative voice made your study of the text(s) more engaging?

Yes

No

Not sure

Please explain the reasons for your answer

9. Does your awareness of the often complex nature and function of the narrator make you think more about other aspects of the text(s) you are studying?

Yes

No

Not sure

Please explain the reasons for your answer

10. Would you say that, for you, a focus on the narrator/narrative voice has been an innovative way of approaching the text(s)?

Yes

No

Not sure

Please explain the reasons for your answer

Questions from the shorter, second survey (administered only to seven English groups) were as follows:

1. When the class focus was on aspects concerning narration, did you find this issue difficult?

Yes

No

Not sure

Please explain the reasons for your answer

2. When the class focus was on aspects concerning narration, did this motivate your study of the text?

Yes

No

Not sure

Please explain the reasons for your answer

3. When the class focus was on aspects concerning narration, did you find this issue to be less relevant than other concerns (such as plot or character)?

Yes

No

Not sure

Please explain the reasons for your answer 
4. Do you think that a focus on narrative issues is more abstract than the study of other aspects of a text such as social, political or gender-related concerns?

Yes

No

Not sure

Please explain the reasons for your answer

5. Was the study of the text more interesting to you through focussing on narrative issues?

Yes

No

Not sure

Please explain the reasons for your answer

Clearly, there are many ways in which responses to such questions can be assessed and interpreted, and this is still more the case when a large number of the questions provided the option for additional comment, which requires distinct analysis. As we are currently engaged in a detailed evaluation of these responses, we are as yet unable to present any definitive data. However, a selection of responses to certain central questions is very illustrative.

For instance, if we consider the results of our first survey $(\mathrm{S} 1)^{2}$, in question 1, which attempts to determine the first area of literary focus that readers engage with, we received just under $60 \%$ of responses indicating that plot was usually the first element of concern for our students. In itself, this is neither problematic nor (of course) surprising, in that a first reading of any literary text can legitimately wish to concern itself with a work's overall storyline. But it is useful in reaffirming the idea that this concern is, indeed, a generally experienced initial response and that, in light of this, one of the fundamental tasks for literature teachers involved in helping their students to attain an advanced level of understanding is precisely to find ways of developing alternative and deeper forms of connecting with a text. In this sense, our results support the views of Davies (2006) who, as we have seen, suggests that students' views on the study of literature reflect 'black and white' assumptions about what this involves: plot is firmly on their radar; other issues would appear not to be so. Moreover, these findings evidence the existing gap between language and literature learning in the foreignlanguage curriculum. The introduction of relatively inexperienced readers to the reading of literature in a foreign language brings in its wake the difficulty of integrating more advanced reading tasks with a more basic training in reading skills. Our challenge, then, is two-fold: we need to remain focused on the reader as well as on the text.

Almost $75 \%$ of respondents confirmed that, for question $8, \mathrm{~S} 1$, which enquires into whether a focus on narrative is thought of as being engaging, this was their perception. 
Comments on this included remarks such as "I like being tricked and I like it most when I am not concerned about it (which is most of the times). Therefore, analysing the text and, within it, the narrator is obviously engaging"; "Discovering more layers or dimensions in a literary work, those that are not readily apparent, is one of the things I enjoy the most of studying literature"; "It is an aspect of texts that you're not even made aware of when you're in high school (and that sometimes you forget about), so it's an exciting and 'new' field of literary exploration. On top of that, studying this aspect of all the different texts we've dealt with enables you to establish comparisons and see differences, influences, options..." and "I can now appreciate some details much more". Our feeling is that this may in part be due to the fact that this focus contributes to - in Hickey and Reiss' (2000) term - a shift in classroom authority away from the centrally 'validated' views of a teacher who interprets the literary work for his or her attentive students and towards a more shared exploration of how a given text actually creates its literary characteristics (in this regard and with these results, we also fully concur with the views of Durant, Mills and Montgomery (1988) concerning the advisability of a hands-on approach to textual enquiry as a means of increasing students' appreciation of the texts under study). It is worth adding at this point that Survey 2 (administered at the end of an annual subject) appears to confirm the positiveness with which literature students receive a focus on narrative. Just over $70 \%$ of respondents agreed that the approach had been motivating for their study and (S2, Q2), and almost $90 \%$ of respondents found the study of their class texts to be more interesting for having taken this approach (S2, Q5). In all events, and even accepting the highly provisional nature of these results, responses in this area are encouraging. A focus on narrative for the discussion of literature seems to draw explicit awareness of the interactive nature of the reading process, providing students with an understanding of certain theoretical issues such as readability, comprehension, and interpretation, and preparing them for a reader-based approach to the text.

Similar percentages hold for S1 questions 9 and 10 (respectively, on whether narrative focus encourages interest in other ambits of interpretation and whether this approach is seen as innovative), with about $75 \%$ of respondents confirming, for both questions, that this approach facilitates their awareness of and access to other aspects of literary study (Q9) and (Q10) that it was a new study focus for them. Taken together, we suggest that these results somewhat challenge certain aspects of the views forwarded by Watson (2005), which propose that students" "initial responses" (p. 96) be given greater centrality in the literature classroom, not—we would emphatically add-because such responses (primarily plot-related, as our 
questionnaire confirms) lack any validity, but rather because our own results point to the limited nature of these reactions, which may act as an obstacle to fuller critical engagement with the text. This clearly provides us with a strong basis for justifying a narrative emphasis in our teaching practice. Such an approach not only offers teachers a means by which to help students progress from description to interpretation, it also allows students and teachers alike to share a critical theoretical background in the discussion of literature. Moreover, it justifies at a theoretical level several teaching strategies used intuitively in the classroom, and strongly suggests that narrative theory is not merely a tool for academic research but - in additionthat it is, in itself, a crucial part of critical reading.

\section{Conclusions}

The conclusions stemming from the results of our MQD work plan are necessarily partial, since data collection and mining are carried out on an on-going basis and will continue beyond the timeframe for the MQD project itself. As such, our current conclusions may give a somewhat distorted view of what inevitably will be a far more complex and modulated picture; nevertheless, these initial indications of the considerably positive view that students seem to have of this approach are highly encouraging. They appear, at least in part, to substantially validate our essential working assumptions as regard students' preliminary understandings of the subject, the motivational factor that a more clearly defined engagement with the subject can contribute, and, with respect to the manner in which an awareness of narrativity may bring with it paths to understanding other related issues in literary study, a better sense of how to approach the study of literature more effectively at university level.

It remains for these provisional conclusions to be borne out by more detailed feedback from our group members, as teachers following this approach, and — as indicated - by a fuller analysis of the student questionnaires. If, as we suspect, the focus on narrative concerns has shown itself to be a substantial inroad to the better and more effective teaching and studying of literature, we will have set down the foundations for further group work in which we would then address the means of developing similar approaches to our current line of enquiry, this time focussing on other aspects of literary analysis that are also of considerable critical significance.

\section{Bibliography}

Brown, M. (2010). The memoir as provocation: A case for 'Me Studies' in undergraduate classes. College Literature 37(3): 121-142. 
Davies, R. (2006). New ways of teaching literature. Retrieved December 02, 2012 from http://www.llas.ac.uk/resources/gpg/2593.

Durant, A., Mills, S., \& Montgomery, M. (1988). Innovations in the teaching of literature (2). New ways of reading: a course innovation at the University of Strathclyde. Critical Quarterly, 30: 11-20.

Fish, S. (1980). Is there a text in this class? Cambridge: Harvard University Press.

Font, C., Gimeno, L., \& Owen, D. (2011). Not just what it means, but also how it means:

Teaching better reading skills to university students of literature. An interuniversity project. ICERI2011 proceedings. In I. Candel Torres, L. Gómez Chova, \& A. López Martínez (Eds.) International Association of Technology, Education and Development (pp. 3217-3222). Madrid: IATED.

Font, C., Gimeno, L., Owen, D., \& Pividori, C. (2012). Reading and meaning: Teaching narration and interpretation in a multilingual context. An interuniversity project. In: L. Gómez Chova, A. López Martínez, \& I. Candel Torres (Eds.) INTED2012 proceedings, (pp. 3292-3297). Valencia: IATED.

Hancox, D. M., \& Muller, V. (2011), Excursions into new territory: Fictocriticism and undergraduate writing. New Writing: The International Journal for the Practice and Theory of Creative Writing 8(2): 147-158.

Hickey, D. J., \& Reiss, D. (Eds.) (2000). Learning literature in an era of change: Innovations in teaching. Sterling, VA: Stylus Publishing.

Meyer, J., \& Land, R. (2003). Threshold concepts and troublesome knowledge: Linkages to ways of thinking and practising within the disciplines. Enhancing TeachingLearning Environments in Undergraduate Courses. Retrieved December 02, 2012 from http://www.tla.ed.ac.uk/etl/docs/ETLreport4.pdf

Mills, D. (2008). Mind the gap: Teaching Othello through creative responses. Pedagogy 8(1): $154-159$.

Severn, S. E. (2008). Ford Madox Ford's The Good Soldier, Creative writing, and teaching the modernist novel in the introductory-level literature classroom. In C.C. Irvine (Ed.) Teaching the novel across the curriculum: A handbook for educators (pp. 130-143). Westport, CT: Greenwood.

Showalter, E. (2003). Teaching Literature. Malden, MA: Blackwell.

Watson, K. (2005). Research and innovation in the teaching of literature in Australian secondary schools: The last thirty years. L1-Educational Studies in Language and Literature, 5(1): 95-103.

Wisker, G., \& Robinson, G. (2009). Encouraging postgraduate students of literature and art to cross conceptual thresholds. Innovations in Education and Teaching International, 46(3): $317-330$.

\footnotetext{
Authors' References:

David Owen (M.A. Edinburgh, M.A. and Ph.D. Universitat Autònoma de Barcelona) is a lecturer in the Department of English Literature at the UAB where he teaches UK and US literature, history and culture. He also teaches a literature component on the UAB's MA in Foreign-Language Teaching for Secondary-Education Teachers, at the Faculty of Education. His research interests focus mainly on English novelistic fiction of the eighteenth and early nineteenth centuries. Particularly, this concerns the history of the English Novel, its origins and development, and - within that - the formal and artistic properties of the epistolary novel as it affected and was affected by socio-political changes in fiction writing and reading. In terms of individual writers, his research is principally interested in the works of Jane Austen. In 2010, he published Rethinking Jane Austen's Lady Susan (Edwin Mellen, New York), the first monographic study of Austen's abandoned epistolary novella. He is currently editing a critical edition of Anna Maria Porter's Walsh Colville, due to be published in 2013. Email: david.owen@uab.cat
} 
Carme Font holds a PhD from the Universitat Autònoma de Barcelona. She is currently Associate Lecturer in the Department of Filologia Anglesa at the UAB. Her primary line of research is early modern women's writing in Seventeenth-century England. She has been a Houghton Fellow at Harvard University. Her latest publications are Antologia de poetisas del Renacimiento Inglés (Cátedra Ediciones, 2013), as well as articles in Literature and Theology (2013) and Revista Manuscrits (2011).

Email: carme.font@uab.cat

Laura Gimeno Pahissa obtained her PhD (2010) from the Universitat Autònoma de Barcelona where she has been teaching since 2001. Her fields of research and teaching are American history and literature. She has also been awarded several research fellowships by international institutions such as the Fulbright Commission and the U.S. Department of State, the John Fitzgerald Kennedy Institut für Amerikastudien (Germany), and the Heidelberg Centre for American Studies (Germany).

Email: laura.gimeno@uab.cat

Cristina Pividori holds an MA and a PhD in English Philology from the Universitat Autònoma de Barcelona. She is currently teaching English for Audiovisual Media at Universitat Politècnica de Catalunya. Her main research interest is World War One literature, specifically the representation of masculine heroism in British autobiographical narratives. She has published in Atlantis (2008, 2010), in the Journal of War and Culture Studies (2009) and in Revista Alicantina de Estudios Ingleses (2012).

Email: mariacristina.pividori@uab.cat

To cite this article:

Owen, D., Font, C., Gimeno, L., \& Pividori, C. (2012). Into the engine room: An inter-university literatureteaching project focussing on narrative. Bellaterra Journal of Teaching \& Learning Language \& Literature, 5(4): 1-19.

\footnotetext{
${ }^{1}$ For a succinct definition, see http://public.wsu.edu/ delahoyd/reader.crit.html. For fuller discussion, see Fish (1980).

2 The specific subjects taken by students who answered this survey were C19 US Literature; Victorian Literature; Literature of the British Romanticism; and Contemporary British Literature.
} 